\title{
The microtubule-depolymerizing agent ansamitocin $P 3$ programs dendritic cells toward enhanced anti-tumor immunity
}

\author{
Kea Martin • Philipp Müller · Jens Schreiner · Spasenija Savic Prince • \\ Didier Lardinois • Viola A. Heinzelmann-Schwarz • \\ Daniela S. Thommen • Alfred Zippelius
}

Received: 17 January 2014 / Accepted: 28 May 2014 / Published online: 7 June 2014

(C) Springer-Verlag Berlin Heidelberg 2014

\begin{abstract}
In addition to direct tumor cell cytotoxicity, chemotherapy can mediate tumor reduction through immune modulation of the tumor microenvironment to promote anti-tumor immunity. Mature dendritic cells (DCs) play key roles in priming robust immune responses in tumor-bearing hosts. Here, we screened a panel of 21 anticancer agents with defined molecular targets for their ability to induce direct maturation of DCs. We identified ansamitocin P3, a microtubule-depolymerizing agent, as a potent inducer of phenotypic and functional maturation
\end{abstract}

K. Martin and P. Müller have contributed equally to this work.

Electronic supplementary material The online version of this article (doi:10.1007/s00262-014-1565-4) contains supplementary material, which is available to authorized users.

K. Martin · P. Müller ( $\bowtie) \cdot$ J. Schreiner · D. S. Thommen ·

A. Zippelius

Cancer Immunology and Biology, Department of Biomedicine,

University Hospital Basel and University of Basel, Basel,

Switzerland

e-mail: ph.mueller@unibas.ch

S. S. Prince

Institute of Pathology, University Hospital Basel, Basel,

Switzerland

D. Lardinois

Department of Surgery, University Hospital Basel, Basel,

Switzerland

V. A. Heinzelmann-Schwarz

Department of Gynecology and Gynecologic Oncology,

University Hospital Basel, Basel, Switzerland

D. S. Thommen $\cdot$ A. Zippelius $(\varangle)$

Department of Medical Oncology, University Hospital Basel,

Petersgraben 4, 4031 Basel, Switzerland

e-mail: alfred.zippelius@usb.ch of DCs. Exposure of both murine spleen-derived and human monocyte-derived DCs to ansamitocin P3 triggered up-regulation of maturation markers and production of pro-inflammatory cytokines, resulting in an enhanced $T$ cell stimulatory capacity. Local administration of ansamitocin P3 induced maturation of skin Langerhans cells in vivo and promoted antigen uptake and extensive homing of tumor-resident DCs to tumor-draining lymph nodes. When used as an adjuvant in a specific vaccination approach, ansamitocin P3 dramatically increased activation of antigen-specific $T$ cells. Finally, we demonstrate that ansamitocin P3, due to its immunomodulatory properties, acts in synergy with antibody-mediated blockade of the $T$ cell inhibitory receptors PD- 1 and CTLA- 4 . The combination treatment was most effective and induced durable growth inhibition of established tumors. Mechanistically, we observed a reduced regulatory $T$ cell frequency and improved $T$ cell effector function at the tumor site. Taken together, our study unravels an immune-based anti-tumor mechanism exploited by microtubule-depolymerizing agents, including ansamitocin $\mathrm{P} 3$, and paves the way for future clinical trials combining this class of agents with immunotherapy.

Keywords Anti-tumor immunity $\cdot$ Dendritic cell maturation - Immunotherapy · Ansamitocin P3 .

Chemotherapy $\cdot$ Microtubule-depolymerizing agent

\section{Introduction}

Recent advances in understanding the anti-tumor immune response have led to major improvements in the field of cancer immunotherapy [1]. In particular, blocking immune checkpoints with monoclonal antibodies such 
as anti-CTLA-4 and anti-PD-1 has emerged as promising strategy that mediates clinically significant responses in a broad variety of cancer types $[2,3]$. Combining conventional chemotherapy with immunotherapies may further improve efficacy [4, 5]. However, many chemotherapeutic agents interfere with anti-tumor immune responses by impairing the clonal expansion of effector lymphocytes or by disturbing the homeostasis of immune cells [6]. This is not surprising, as classical chemotherapeutic agents were originally selected based on their ability to interfere with metabolic processes, DNA maintenance, gene transcription as well as RNA and protein biosynthesis. On the other side, the tumor microenvironment itself may actively impede effector cell function, thereby limiting the efficacy of immune-based therapies [7]. With regard to this, it has recently become evident that some chemotherapeutic agents and molecular targeted therapies are capable of interfering with tumor-host interactions, thus mediating therapeutic effects by promoting anti-tumor immune responses [8]. These therapies may act on tumor cells by modulating their propensity to elicit anti-tumor immune responses; or alternatively, immune effector cells may be stimulated, either directly or by relieving immunosuppressive mechanisms within the tumor microenvironment. Therefore, the combination of selected chemotherapy partners with immunotherapies has great clinical potential, but requires a deeper understanding of the immune-promoting nature of these agents.

Dendritic cells (DCs) are specialized antigen-presenting cells with a pivotal role in the initiation and maintenance of anti-tumor immune responses. Their unique ability to induce primary immune responses makes them ideal candidates for generating therapeutic immunity against cancer [9]. Of note, activated (mature) DCs promote the differentiation of antigen-specific $T$ cells into $T$ cells that execute broad and efficient effector functions; non-activated (immature) DCs, however, may rather induce a state of tolerance through either deletion of $T$ cells or differentiation of regulatory/suppressor $T$ cells. Hallmarks of DC maturation include a limited capacity to efficiently capture antigens, increased expression of surface MHC class II and costimulatory molecules, and the ability to secrete cytokines and to migrate into draining lymph nodes. Importantly, tumors may prevent the generation of sustained anti-tumor immunity by inducing DC dysfunction through a variety of mechanisms [10]. Along with the identification of chemotherapeutic agents capable of triggering immunogenic cell death, DCs have been recognized as critical players in therapy-induced anti-tumor immunosurveillance. Particularly, anthracyclines, oxaliplatin, and mafosfamide are able to induce a series of molecular signatures on dying tumor cells, which can promote DC-mediated anti-tumor immunity via such endogenous vaccination [11]. A different, equally attractive therapeutic scenario harnesses the potential of anticancer agents to directly promote DC differentiation and maturation, even in the absence of signals from dying tumor cells. Mechanistically, these agents reinstate immunosurveillance by driving a distinct DC maturation program, besides their ability to potently inhibit tumor cell growth. Few studies have investigated the pharmacological effect of different anti-tumor agents on DC function to date. Recent studies have identified cytotoxic agents including anthracyclines [12] and the mitotic spindle inhibitor vinblastine as potent activators of DC maturation [13-15]. On the other side, some anti-tumor therapeutics do block DC maturation and therefore antagonize anti-tumor immunity. Such inhibitory effects on DC function are seen with the estrogen receptor modulators tamoxifen and raloxifene [16] and the anti-angiogenic tyrosine kinase inhibitor sorafenib, but not sunitinib [17].

To investigate whether the effect of specific chemotherapeutics on DC maturation is related to their compound class, we tested a panel of 21 cytotoxic compounds of distinct classes for their ability to induce activation of murine and human DCs. Consistent with previous data on vinblastine and colchicine [13-15], all tested microtubule-destabilizing compounds were able to induce DC stimulation, whereas microtubule-stabilizing compounds, such as the taxanes, did not exert this effect. Among microtubule-destabilizing agents, the maytansinoid ansamitocin P3 was identified as the most potent inducer of DC maturation, which resulted in augmentation of antitumor immunity in tumor-bearing hosts. By combining $T$ cell co-inhibitory blockade with ansamitocin P3 treatment, we were able to induce rejection of tumors and to characterize the cellular and molecular mechanisms driving this response.

\section{Material and methods}

Reagents and antibodies

Twenty-one anticancer agents of different classes were tested (supplementary Table 1). Drugs were dissolved in DMSO $(10 \mathrm{mmol} / \mathrm{L})$ and tested at various concentrations with a final maximum DMSO concentration of $0.5 \%$. Endotoxin-free ovalbumin (OVA) protein (EndoGrade) was purchased from Hyglos Biotechnology, Germany. Escherichia coli 026:B6 lipopolysaccharide (LPS), FITCconjugated dextran, and Corynebacterium diphtheriae diphtheria toxin (DT) were purchased from Millipore, T4 peptide (SIITFEKL) from Eurogentec, and $\mathrm{OVA}_{323-339}$ peptide from Peptides and Elephants. $\alpha$-CTLA-4 (clone 9D9) and $\alpha$-PD1 (clone RMP1-14) antibodies and matched isotype controls for in vivo treatment were produced by BioXCell. 
Cell lines

The immature mouse DC cell line SP37A3 (Merck KGaA, [18]) was cultured in Iscove's modified Dulbecco's medium (IMDM; Sigma) supplemented with $10 \%$ heat-inactivated and endotoxin-tested FBS (PAA), sodium pyruvate (Gibco), penicillin/streptomycin, L-glutamine mix (Gibco), Eagle's minimum essential medium (MEM), nonessential amino acids (Sigma), Ciproxin (Bayer), and $0.05 \mathrm{mM}$ 2-mercaptoethanol (Gibco). IMDM complete medium was supplemented with $20 \mathrm{ng} / \mathrm{mL}$ recombinant mouse GM-CSF and $20 \mathrm{ng} / \mathrm{mL}$ recombinant mouse M-CSF (both Peprotech). The murine tumor cell line EG-7 was obtained from ATCC (Virginia). Murine MC38 tumor cells were provided by Mark Smyth (Peter MacCallum Cancer Centre, Melbourne, AU). 3LL-Thy1.1-OVA cells were provided by Douglas T. Fearon (Cancer Research UK Centre, Cambridge, UK). Cells were cultured in Dulbecco's modified Eagle's medium (DMEM) with Glutamax (Gibco) supplemented with $10 \%$ heat-inactivated FBS, sodium pyruvate, penicillin/streptomycin, L-glutamine mix, MEM, nonessential amino acids, Ciproxin and $0.05 \mathrm{mM}$ 2-mercaptoethanol.

\section{Mice}

C57BL/6 mice were obtained from Charles River Laboratories (Wilmington, MA) and OT-II TCR transgenic mice from J. Pieters (Biozentrum, University of Basel, Switzerland). OT-I TCR, recombination activating gene 2 deficient $\left(\operatorname{Rag} 2^{-/-}\right)$, interferon- $\gamma$-receptor deficient (IFN- $\gamma \mathrm{R}^{-/-}$), CD11c-diphtheria toxin receptor (DTR)/GFP transgenic mice, and C57BL/6-Ly5.1 mice were bred in-house (Department of Biomedicine, University Hospital Basel, Switzerland). All animals were housed under specific pathogen-free conditions and in accordance with Swiss federal regulations.

\section{Generation of bone marrow DCs}

Bone marrow cells $\left(2 \times 10^{6} / 10 \mathrm{~mL}\right.$ complete DMEM medium) from $\mathrm{C} 57 \mathrm{BL} / 6 \mathrm{WT}$ mice were cultured in the presence of $20 \mathrm{ng} / \mathrm{mL}$ recombinant murine GM-CSF (Peprotech) and were activated at day 7 of culture. After 24-h stimulation, the DC phenotype was assessed by flow cytometry and DCs were used in co-culture assays.

Activation of human and murine DCs in vitro

Peripheral blood mononuclear cells (PBMCs) from healthy donors (Blood Transfusion Center, University Hospital Basel) were isolated from buffy coats by density gradient separation (Histopaque 1077, Sigma). CD14 ${ }^{+}$monocytes were purified with anti-CD14-coated microbeads
(Miltenyi Biotec, Germany) and induced to differentiate to DCs in a 5- to 6-day culture in complete RPMI 1640 supplemented with $10 \%$ heat-inactivated and endotoxin-tested FBS (PAA), sodium pyruvate, penicillin/streptomycin, L-glutamine mix, MEM nonessential amino acids, $0.05 \mathrm{mM}$ 2-mercaptoethanol, $50 \mathrm{ng} / \mathrm{mL}$ GM-CSF, and $250 \mathrm{U} / \mathrm{mL}$ recombinant human interleukin 4 (rhIL-4; Peprotech). DC purity and maturation were routinely checked by means of flow cytometric analysis.

Murine SP37A3 DCs and day 6 human monocytederived DCs (moDCs) were incubated $\left(6 \times 10^{4}\right.$ cells/ well) with cytotoxic compounds $(0.1 \mu \mathrm{M})$ or LPS (500 ng/ $\mathrm{mL}$ ) as positive control. After $24 \mathrm{~h}$, the DC phenotype was assessed by flow cytometry. Dead cells were excluded by SytoxGreen ${ }^{\circledR}$ (Invitrogen) staining.

\section{Cytokine detection}

IL-1 $\beta$, IL-6, and IL-12 in supernatants of murine DC cultures were detected by standard sandwich ELISA procedures using commercially available kits (eBioscience). Furthermore, cytokine secretion of SP37A3 DCs or bone marrow-derived DCs (BMDCs) was characterized by flow cytometric analysis. For this purpose, cells were cultured in the presence of ansamitocin P3 $(0.01 \mu \mathrm{M})$ or LPS (500 ng/ $\mathrm{mL}$ ) for $20 \mathrm{~h}$ (IL-12), $15 \mathrm{~h}$ (IL-6), or $6 \mathrm{~h}$ (IL-1 $\beta$ ). Brefel$\operatorname{din} \mathrm{A}$ was added for the whole incubation time (IL-1 $\beta$ and IL-6) or for the last $6 \mathrm{~h}$ of culture (IL-12). Cell surface staining of MHCII and CD11c was performed following fixation, permeabilization, and intracellular cytokine staining.

In situ maturation of skin Langerhans cells

Twenty $\mu \mathrm{L}$ ansamitocin P3 (4 $\mu \mathrm{g} /$ mouse) or PBS was injected intradermally (i.d.) into the ears of C57BL/6 mice (three mice/group, two ears/point). Ear skin specimens were harvested after $24 \mathrm{~h}$, and epidermal sheets were separated and digested with accutase (PAA), collagenase IV (Worthington), hyaluronidase (Sigma), and DNAse type IV (Sigma) for flow cytometric analysis. Single-cell suspensions were stained with anti-CD45, anti-CD11c, antiMHC-II, and anti-CD86 antibodies (BD Biosciences). Dead cells were excluded with SytoxBlue ${ }^{\circledR}$ (Invitrogen) staining. For immunofluorescence, epidermal sheets were prepared as previously described [19], stained overnight with anti-MHC-II and anti-CD86 antibodies, and analyzed using an Olympus BX61 fluorescence microscope.

In vitro stimulation of OVA-specific OT-I and OT-II T cells

SP37A3 DCs or BMDCs (day 7) were pulsed with OVA full-length protein $(0.1 \mathrm{mg} / \mathrm{mL})$ for $1 \mathrm{~h}$ and activated 
with $0.01 \mu \mathrm{M}$ ansamitocin P3 (24 h). Activated DCs were washed and co-cultured with $\mathrm{CD} 8^{+}$OT-I or $\mathrm{CD}^{+}{ }^{+} \mathrm{OT}-\mathrm{II} T$ cells purified from lymph nodes and spleens of OT-I and OT-II transgenic mice, respectively. $T$ cells were isolated using $T$ cell enrichment kit (EasySep, Stemcell Technology). $\mathrm{CD}^{+}$and $\mathrm{CD} 4^{+} T$ cells were loaded with the proliferation dye eFluor670 (eBioscience) prior to co-culture. Proliferation was assessed after 3 days using flow cytometry.

Tracking of DC migration to tumor-draining LNs

$2 \times 10^{5}$ EG-7 tumor cells were injected s.c. into the right flank of C57BL/6 mice. When tumors reached an average size of size of approximately $50-60 \mathrm{~mm}^{3}$, ansamitocin P3 (4 $\mu \mathrm{g} /$ mouse) or PBS (control) together with FITC-conjugated dextran (100 $\mu \mathrm{g} /$ mouse; Sigma) was injected intratumorally. Tumor-draining and non-draining LNs were isolated after $48 \mathrm{~h}$, and single-cell suspensions were analyzed for CD45, CD11c, CD11b, MHC-II, and CD86 by flow cytometry. Dead cells were excluded by SytoxBlue ${ }^{\circledR}$ staining.

In vivo activation of antigen-specific OT-I T and OT-II cells

$\mathrm{CD}^{+}$or $\mathrm{CD}^{+} T$ cells from LNs and spleen of naïve OT-I or OT-II transgenic mice (Ly5.2), respectively, were labeled with eFluor670 and adoptively transferred into C57BL/6Ly5.1 mice $\left(2 \times 10^{6}\right.$ cells/mouse). Twenty-four hour later, mice were immunized with $25 \mu \mathrm{g}$ OVA-T4 peptide (SIITFEKL; low-affinity variant of SIINFEKL [20]) and OVA $_{323-339}$ peptide together with ansamitocin P3 $(4 \mu \mathrm{g} /$ mouse) or LPS (25 $\mu \mathrm{g} /$ mouse) via tail-base injection. Single-cell suspensions from "vaccine"-draining inguinal LNs were prepared 3 days after transfer, and proliferation of OT-I CD $8^{+}$as well as OT-II CD $4^{+} T$ cells was assessed by flow cytometry.

Human mixed lymphocyte reaction

Human moDCs were incubated with ansamitocin P3 (1 nM) or LPS $(500 \mathrm{ng} / \mathrm{mL})$ during differentiation (d4-d6), washed, irradiated (30 Gy), and plated in RPMI1640 supplemented with $10 \%$ human serum (AB). $\mathrm{CD}^{+} T$ cells from healthy donors were purified as described [21] and labeled with eFluor670. Allogeneic $\mathrm{CD}^{+} T$ cells were added (day 6) to cultures of activated DCs (DC/T ratio of 1:25). $T$ cell proliferation was assessed after 4 days by flow cytometry.

Tumor challenge and therapeutic protocol

Seven- to ten-week-old mice were injected subcutaneously (s.c.) into the right flank with $2.5-5 \times 10^{5}$ tumor cells in
$100 \mu \mathrm{L}$ phenol red-free DMEM (Gibco). WT C57B1/6, $\operatorname{Rag} 2^{-1-}$, and IFN- $\gamma \mathrm{R}^{-1-}$ mice bearing s.c. EG-7 tumors received intratumoral injections of ansamitocin $\mathrm{P} 3(0.3 \mathrm{mg} /$ $\mathrm{kg}$ ) or vehicle (PBS) on day 10. WT and CD11c-DTR/GFP mice bearing s.c. 3LL-Thy1.1-OVA tumors were treated i.v. with ansamitocin P3 $(0.3 \mathrm{mg} / \mathrm{kg})$ on day 16 . DT (4 ng/g body weight) or PBS (control) was injected i.p. on day 15 . MC38-bearing mice were administered ansamitocin P3 $(0.3 \mathrm{mg} / \mathrm{kg}$ i.v. $)$ on days 16,17 , and 18 after tumor challenge, alone or combined with anti-CTLA4/anti-PD1 antibodies (250 $\mu \mathrm{g}$ each administered i.p. on days 20, 22, 25, and 28). Anti-CTLA4/anti-PD1 antibodies administered without ansamitocin P3 were given on days 16, 18, 21, and 24 . Tumor growth was measured every second day and volume calculated according to the formula: $D / 2 * d^{2}$ with $D$ and $d$ being the longest and shortest tumor diameter in $\mathrm{mm}$, respectively. Mice were euthanized when tumors reached a size of $1,500 \mathrm{~mm}^{3}$.

Analysis of tumor-infiltrating lymphocytes

Seven- to ten-week-old mice were injected s.c. into the right flank with $5 \times 10^{5}$ MC38 tumor cells in $100 \mu \mathrm{L}$ phenol red-free DMEM. Ansamitocin P3 $(0.3 \mathrm{mg} / \mathrm{kg}$ on days 16,17 , and 18) was given alone or combined with anti-CTLA4/anti-PD1 (250 $\mu$ g each i.p. on days 20, 22, and 24). Mice receiving antibodies alone were treated on days 16,18 , and 20 . On day 26 , tumors were digested as described previously for epithelial sheets and single-cell suspensions analyzed by flow cytometry. For detection of IFN- $\gamma$-producing cells, single-cell preparations were cultured overnight in the presence of anti-CD3/CD28 antibodies and Monensin (Biolegend).

Statistics

$T$ cell proliferation and DC activation marker expression were compared using two-tailed paired Student's $t$ test. Kaplan-Meier survival plots were analyzed using a $\log$ rank test (Mantel-Cox). $P<0.05$ was considered significant for all tests.

\section{Results}

Microtubule-depolymerizing compounds stimulate CD86 expression in DCs

Therapeutic agents investigated included microtubule-stabilizing (paclitaxel, patupilone A/B, docetaxel, D-64131) and microtubule-destabilizing (Vinca alkaloids, combretastatinA4-phosphate, ansamitocin P3) agents, COX inhibitors (naproxen, celecoxib), the angiokinase inhibitor BIBF1120, 

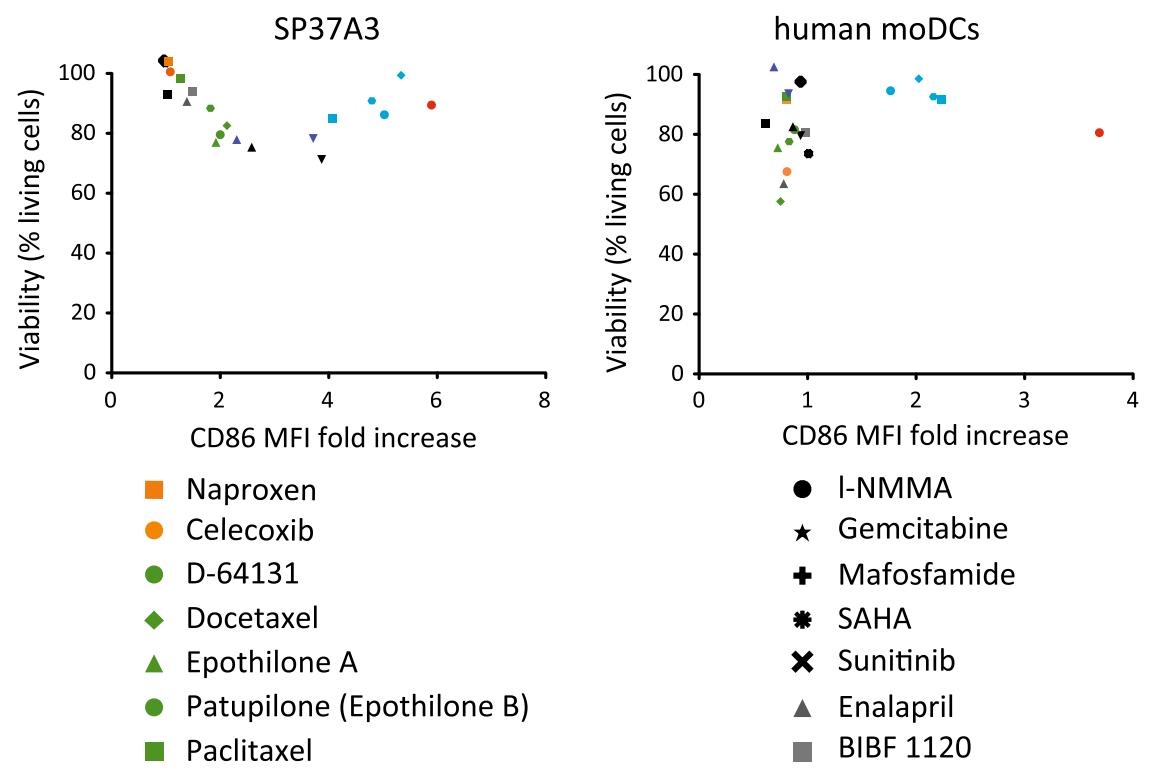

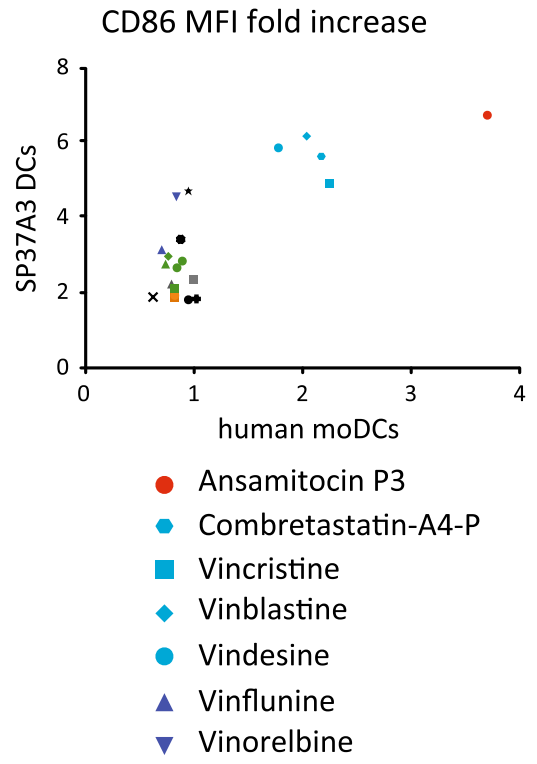

Fig. 1 Identification of ansamitocin P3 as potent inducer of DC maturation in vitro. SP37A3 murine DCs and human moDCs were incubated with the indicated chemotherapeutic compounds $(0.1 \mu \mathrm{M})$ for $24 \mathrm{~h}$. Expression of CD86 on murine SP37A3 DCs and human moDCs after exposure to chemotherapeutic agents was correlated with viability (left and middle panel). Mean fluorescence intensity

the angiotensin-converting enzyme inhibitor enalapril, the nitric oxide synthase inhibitor I-NMMA, the DNA replication blocker gemcitabine, the alkylating agent mafosfamide, the receptor tyrosine kinase inhibitor sunitinib, and the histone deacetylase inhibitor SAHA. To delineate which of these compounds could induce DC maturation, primary murine SP37A3 splenic DCs and human moDCs were incubated with drugs at concentrations ranging from 1 to $0.0001 \mu \mathrm{M}$. Cell viability and expression of CD86 were assessed by flow cytometry after $24 \mathrm{~h}$ as shown for a drug concentration of $0.1 \mu \mathrm{M}$ in Fig. 1. Ansamitocin P3 (red) was by far the most potent inducer of CD86 on murine and human DCs. Cell viability was only modestly affected at this drug concentration. Of note, all microtubule-destabilizing agents (blue/red) displayed a pronounced capacity to up-regulate CD86 on DCs, in contrast to microtubule-stabilizing agents (green) and compounds of other classes.

Ansamitocin P3 triggers phenotypic and functional maturation of murine DCs in vitro and in vivo

To determine whether ansamitocin P3 induced the full spectrum of phenotypic maturation markers on DCs, SP37A3 DCs were incubated with ansamitocin P3 for $24 \mathrm{~h}$. Subsequently, the expression of CD80, CD86, CD40, and MHCII was measured. Compared with untreated controls, ansamitocin P3 significantly increased expression of all DC maturation markers (Fig. 2a). In addition, we noted an
(MFI) fold change in murine SP37A3 DCs versus MFI fold change in human moDCs is shown in the right panel. MFI was assessed by flow cytometry; graphs show fold change of MFI compared with mocktreated cells, which were set as 1 . Data are representative of two independent experiments with similar results

increased production of the pro-inflammatory cytokines IL-1 $\beta$, IL-6, and IL-12 determined by ELISA (left panels) and by intracellular cytokine staining as detected by flow cytometry (right panels; Fig. 2b). Expression of the costimulatory molecules CD80 and CD86 as well as production of all three cytokines was induced to a similar degree by ansamitocin P3 and LPS on SP37A3 DCs. Accordingly, we found a similar up-regulation of maturation markers and cytokines in mouse BMDCs treated with ansamitocin P3 (Supplementary Figure 1A, B). Furthermore, ansamitocin P3 induced in vivo maturation of skin Langerhans cells (LCs) in the ears of C57BL/6 mice (Fig. 2c, d). Epidermal sheets prepared $24 \mathrm{~h}$ after injection of $4 \mu \mathrm{g}$ ansamitocin P3 exhibited increased induction of CD86 and increased expression of MHCII compared with controls. Immunofluorescence additionally revealed an enlarged cell size and altered DC morphology such as elongation of dendrites and a decrease in LC density, which may indicate migration of LCs to draining LNs.

To investigate whether ansamitocin P3-matured DCs displayed enhanced antigen-presenting capacity and activation of $T$ cells in vitro, CD4 ${ }^{+}$OT-II $T$ cells were co-cultured with SP37A3 DCs, which were pulsed with full-length endotoxin-free OVA protein and subsequently treated with ansamitocin P3. Flow cytometry revealed that ansamitocin P3-treated DCs triggered strong proliferation of $T$ cells, comparable to the effect observed with LPS pre-treatment (Fig. 2e), which underscores the potential of ansamitocin 
A
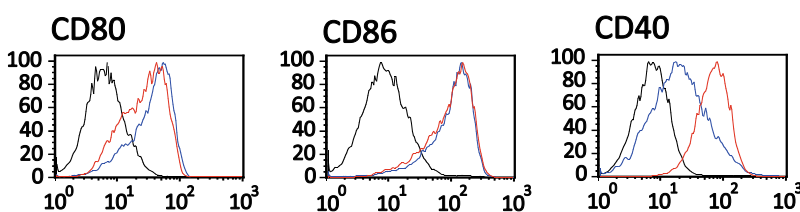

Control

$\square$ Ansamitocin P3

$\square$ LPS
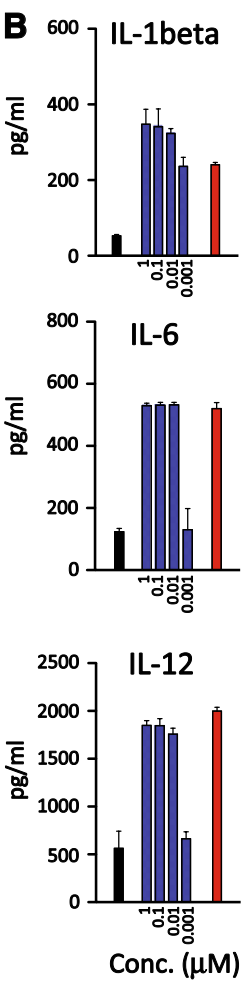

C $\mathrm{MHCII}$
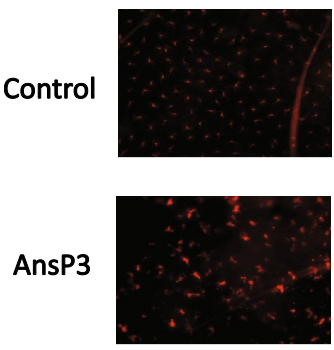

E OT-IIT cells: OVA protein
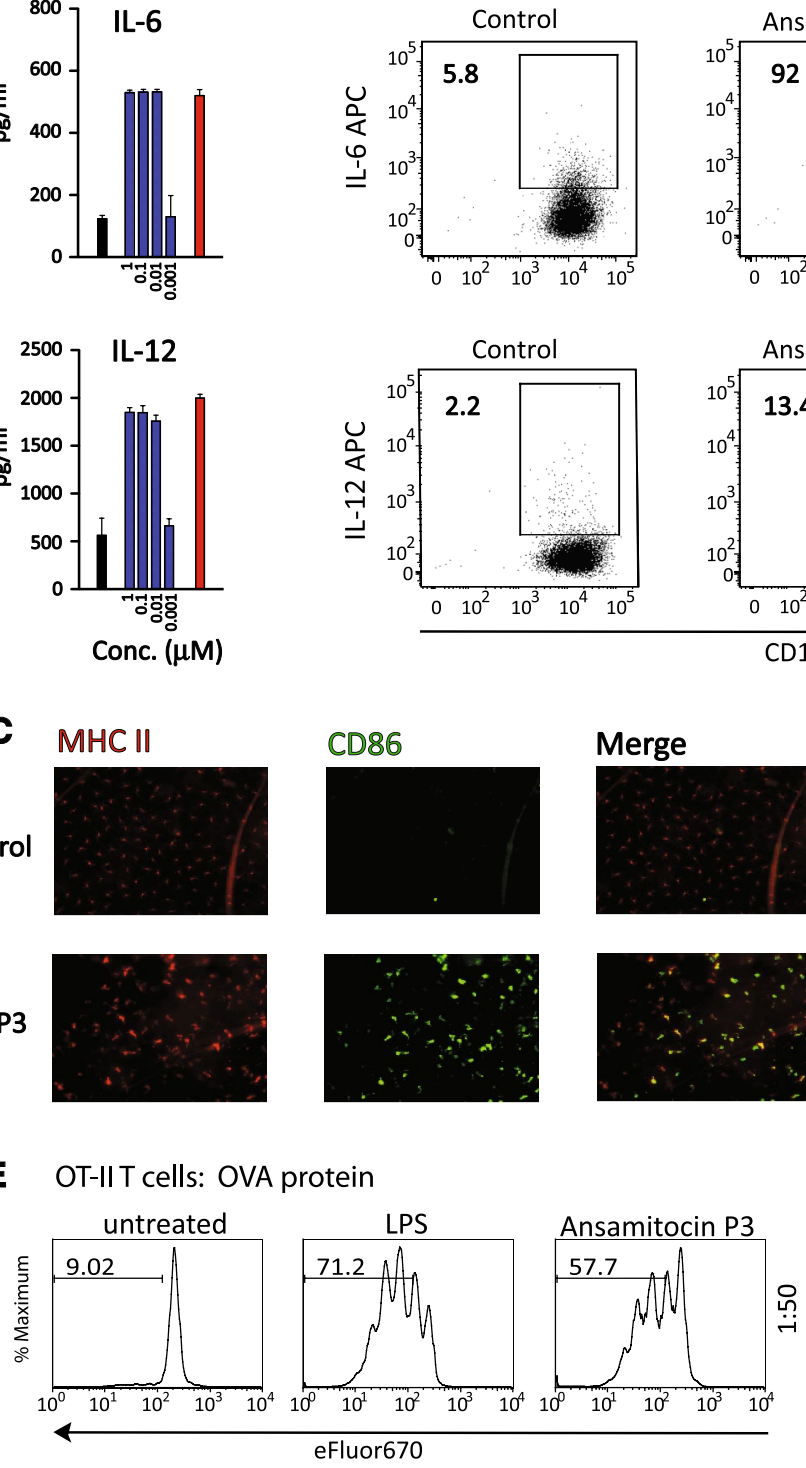

CD86
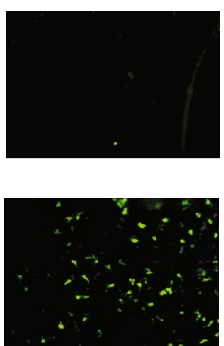
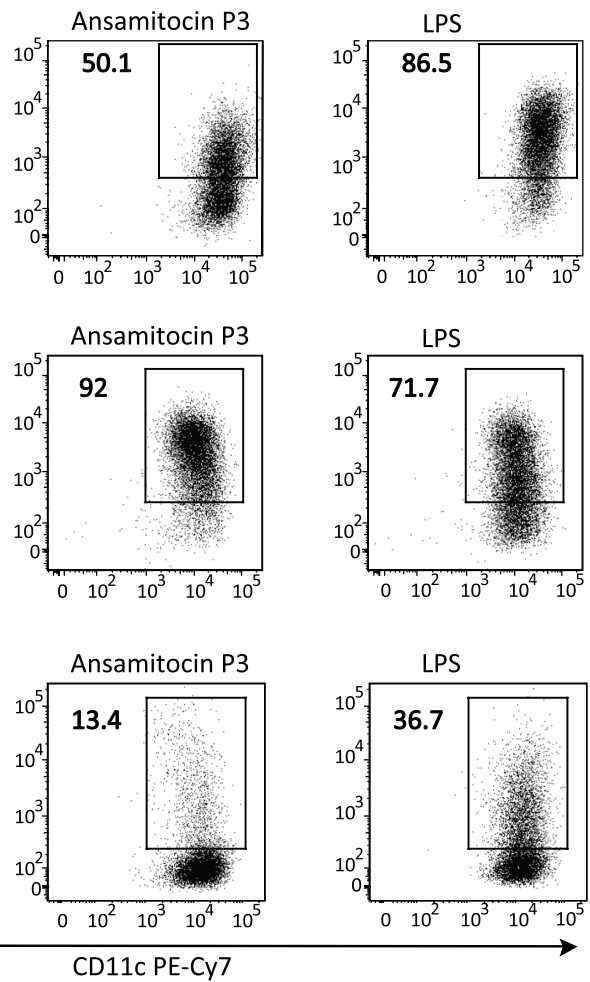

Merge
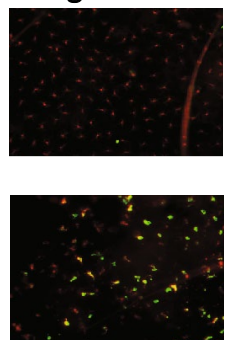

D CD86
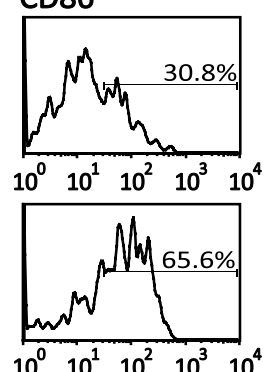
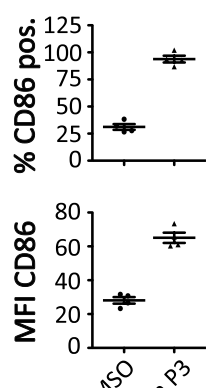

P3 to boost antigen-specific $T$ cell responses). Similarly, ansamitocin P3-treated, OVA protein-loaded BMDCs induced strong proliferation of $\mathrm{CD}^{+}{ }^{+} \mathrm{OT}-\mathrm{II} T$ cells as well as $\mathrm{CD} 8^{+}$OT-I $T$ cells (Supplementary Figure 1C). Minimal
$T$ cell proliferation was seen with protein-loaded untreated DCs, indicating that ansamitocin P3 does not interfere with antigen processing and presentation by DCs. These data indicate that ansamitocin P3-treated DCs efficiently 
4Fig. 2 Ansamitocin P3 induces phenotypic and functional maturation of SP37A3 murine DCs and enhances stimulation of antigenspecific $T$ cells. a Expression of MHCII and the co-stimulatory molecules CD80, CD86, and CD40 by SP37A3 murine DCs after exposure $(24 \mathrm{~h})$ to ansamitocin P3 $(0.1 \mu \mathrm{M})$ or LPS $(500 \mathrm{ng} / \mathrm{mL})$ as positive control. Data show one histogram representative of at least five independent experiments. b Secretion of IL-1 $\beta$, IL-6, and IL-12 was assessed in supernatants from cultures as described in (a) using ELISA (left panels) as well as by intracellular cytokine staining for flow cytometry detection (right panels). $\mathbf{c}+\mathbf{d}$ Ansamitocin P3 (4 $\mu \mathrm{g}$ /animal) or vehicle alone was injected intradermally into the ears of C57BL/6 mice (four mice per group, two ears per point). Ear skin specimens were harvested $24 \mathrm{~h}$ later, and epidermal sheets were either fixed in acetone, stained for MHCII (red) and CD86 (green), and analyzed by immunofluorescence c, or enzymatically digested and stained for CD45, CD11c, MHCII, and CD86 for flow cytometric analysis d. Data show the mean $(n=2)$ of $\% \mathrm{CD}^{\text {high }} 6^{\text {cells and }}$ MFI of $\mathrm{CD} 86$ within the $\mathrm{CD} 45^{+} \mathrm{CD} 11 \mathrm{c}^{+} \mathrm{MHCII}^{+}$population per data point. Control indicates mock-treated mice. Three experiments were performed with similar results. Mean $\pm \mathrm{SD}$ of one representative experiment is shown. e Pre-treatment of murine SP37A3 DCs with ansamitocin P3 induced enhanced activation of antigen-specific $T$ cells. DCs were loaded with OVA protein and treated with ansamitocin P3 $(0.01 \mu \mathrm{M})$ or LPS $(500 \mathrm{ng} / \mathrm{mL})$ prior to irradiation and addition to microcultures of $\mathrm{CD}^{+}$OT-II $T$ cells. The DC/T cell ratio is indicated. Proliferation of OT-II $T$ cells was assessed by flow cytometry. Data show representative histograms from one of at least three independent studies

process and present antigens on both MHC class II and class I, and the latter pathway is commonly referred to as cross-presentation.

Ansamitocin P3 stimulates LN homing of tumor-resident DCs and activates $T$ cells in vivo

Migration of primed DCs to tumor-draining LNs and subsequent activation of antigen-specific $T$ cells are critical steps in the establishment of an effective anti-tumor immune response [9]. To determine the migratory potential of ansamitocin P3-treated tumor-resident DCs, FITC-labeled dextran (FITC-Dx), a high-molecular-mass carbohydrate, was used as model antigen. FITC-Dx is endocytosed in an early phase of DC activation [22]. FITC-Dx with either ansamitocin P3 or vehicle was injected into established s.c. EG-7 tumors and tumor-draining LNs were examined for the presence of FITC $^{+}$DCs after $48 \mathrm{~h}$ by flow cytometry. Significantly more LN-resident DCs were FITC-Dx/ CD86-positive in ansamitocin P3-treated mice (20\%) compared with vehicle control-treated mice $(0.3 \%$; Fig. $3 a, b)$. FITC-Dx-bearing DCs were not detected in non-tumordraining LNs in either case, arguing for local, tumor-selective effects of ansamitocin P3 treatment (data not shown). Enhanced activation of antigen-specific $T$ cells in the presence of ansamitocin P3 was confirmed in vivo: Transgenic $\mathrm{CD}^{+}$and $\mathrm{CD}^{+} T$ cells specific for OVA isolated from OT-I to OT-II mice, respectively, were adoptively transferred into Ly5.1 congenic recipient mice, which were immunized with a weak agonist peptide derived from the original OVA peptide SIINFEKL for OT-I $T$ cells [20] and the natural $\mathrm{OVA}_{323-339}$ peptide for OT-II i cells together with ansamitocin P3, LPS, or vehicle (PBS). Both ansamitocin P3 and LPS effectively induced strong proliferation of OT-I and OT-II $T$ cells after 3 days (Fig. $3 \mathrm{c}$ ).

Human DCs stimulated by ansamitocin P3 undergo maturation and activate allogeneic $T$ cells

To investigate the stimulatory effects of ansamitocin P3 on human DCs, monocyte-derived DCs were exposed to ansamitocin P3 and analyzed for up-regulation of HLADR and the co-stimulatory molecules CD86, CD83, and CD40. Similar to murine DCs, ansamitocin P3 treatment up-regulated expression of all four maturation markers on human moDCs in a concentration-dependent fashion (Fig. 4a), while DC viability was not significantly affected by ansamitocin P3 at the indicated concentrations, as determined by SytoxGreen ${ }^{\circledR}$ staining (data not shown). To test moDC functionality in mixed lymphocyte cultures, ansamitocin P3-treated moDCs were co-cultured with allogeneic $\mathrm{CD}^{+} T$ cells (DC/T cell ratio of $\left.1: 25\right)$. Ansamitocin P3 or LPS pre-treated DCs significantly increased $T$ cell proliferation compared with untreated moDC controls (Fig. 4B).

Therapeutic efficacy of ansamitocin P3 is dependent on $\mathrm{CD} 11 \mathrm{c}^{+} \mathrm{DCs}$, interferon- $\gamma$, and adaptive immune cells

Both innate and adaptive immunity critically contribute to treatment outcomes of several chemotherapeutic compounds such as anthracyclines and histone deacetylase inhibitors [23, 24]. To determine the importance of the adaptive immune system (mainly $T$ and B cells) and IFN- $\gamma$ for the treatment efficacy of ansamitocin P3, mice bearing s.c. EG-7 tumors $\left(\sim 80 \mathrm{~mm}^{3}\right)$ were injected intratumorally with ansamitocin P3 $(0.3 \mathrm{mg} / \mathrm{kg})$. Ansamitocin P3 significantly delayed tumor growth in syngeneic immunocompetent WT C57BL/6 mice compared with controls, whereas in immune-deficient $\mathrm{Rag} 2^{-/-}$or IFN- $\gamma \mathrm{R}^{-/-}$mice this effect was clearly reduced (Fig. 5a), a finding that directly implicates an involvement of the adaptive immune system in the growth inhibitory effects of ansamitocin P3.

To confirm that DCs are indeed required for tumor growth inhibition upon ansamitocin P3 treatment, we depleted CD11 ${ }^{+}$cells using CD11c-DTR/GFP mice [25]. WT and CD11c-DTR/GFP mice bearing 3LL-Thy1.1OVA tumors were treated with DT with or without ansamitocin P3. Tumor growth suppression by ansamitocin P3 in $\mathrm{CD} 11 \mathrm{c}^{+}$DC-depleted mice was significantly reduced compared with similarly treated WT mice (Fig. 5b). These data suggest that DCs are critically required for the anti-tumor effects of ansamitocin P3 against solid malignancies. 

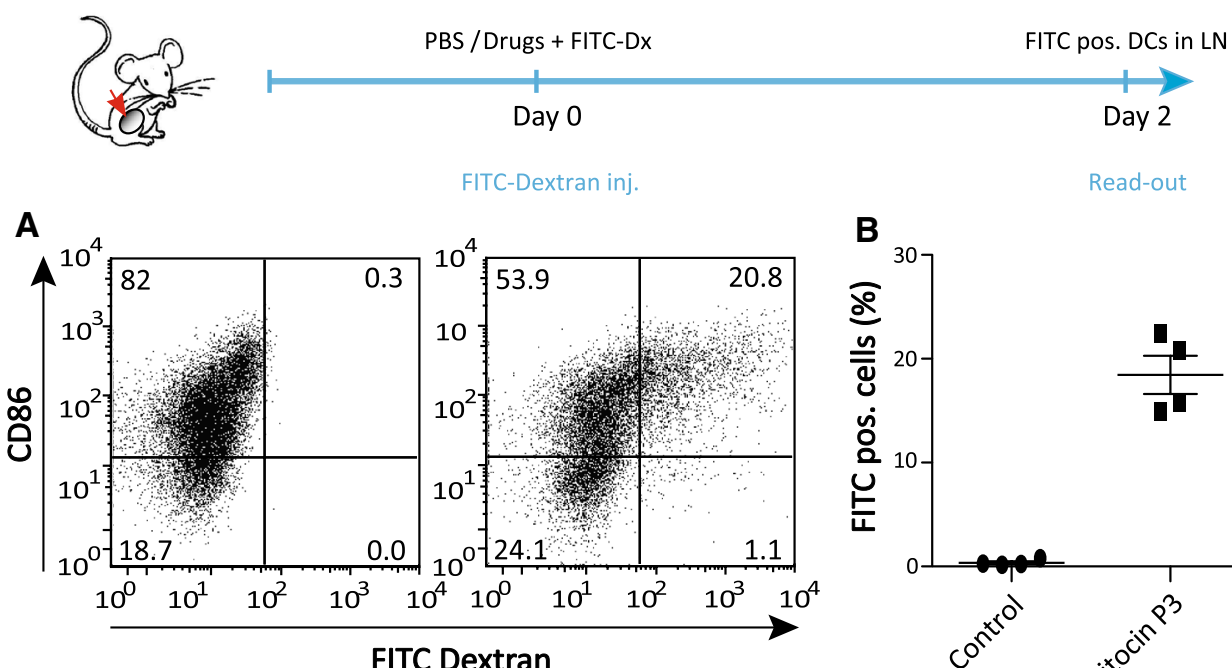

C
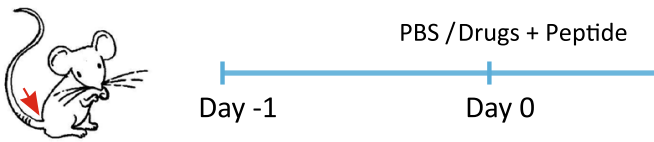

$2 \times 10^{6}$ OT-I/II T cells Immunization
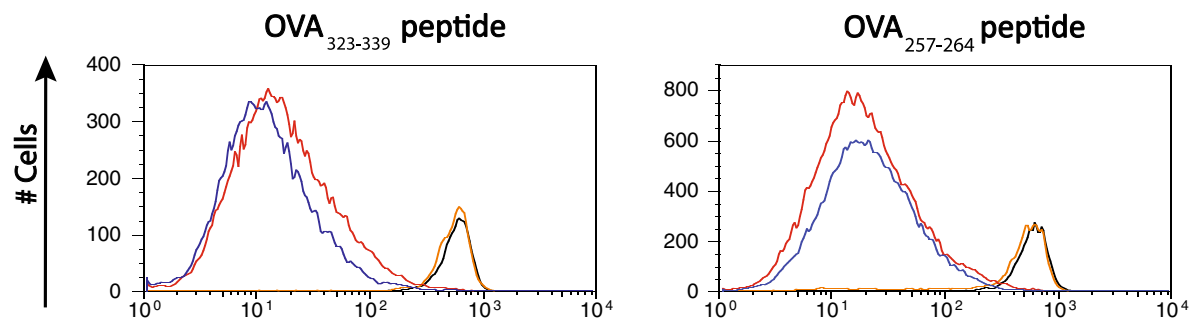

efluor 670

- Control - Peptide — Ansamitocin P3 + Peptide — LPS + Peptide

Fig. 3 DC homing to tumor-draining LNs and enhanced in vivo $T$ cell responses after ansamitocin P3 treatment. a + b FITC-conjugated dextran suspended in vehicle alone (PBS/DMSO), in vehicle containing ansamitocin P3 (4 $\mu \mathrm{g}$ per mouse) was injected intratumoral into C57BL/6 mice with established s.c. EG-7 tumors. Fortyeight hour later, tumor-draining LNs were examined for the presence of FITC-labeled dextran-bearing DCs $\left(\mathrm{CD} 45^{+} \mathrm{CD} 11 \mathrm{c}^{+} \mathrm{MHCII}^{+}\right)$ by flow cytometry. a Representative dot plots depict FITC $^{+}$DCs detected in tumor-draining LNs after PBS/DMSO (left) or ansamitocin P3 (right) injection. b Graphs summarize percent of FITC $^{+}$ DCs from one experiment; representative results from one of three experiments are shown. c eFluor670-labeled $T$ cells from LNs of

Therapeutic synergy of ansamitocin P3 with blockade of PD-1/CTLA-4 inhibitory pathways results in improved intratumoral $T$ cell effector function

Given the critical role of adaptive immunity for the efficacy of ansamitocin P3 treatment, we hypothesized that a combination of ansamitocin P3 with antibodies blocking the $T$ cell checkpoint inhibitors CTLA-4 and PD-1 may provide greater naïve OT-I or OT-II transgenic mice were adoptively transferred into C57BL/6-Ly5.1 recipient mice. After $24 \mathrm{~h}$, mice were immunized via tail-base injection of $25 \mu \mathrm{g}$ OVA-T4 peptide (SIITFEKL) or $5 \mu \mathrm{g}$ $\mathrm{OVA}_{323-339}$ peptide in the absence (PBS/DMSO) or presence of maturation stimuli [ansamitocin P3 (4 $\mu \mathrm{g}$ per mouse), or LPS (25 $\mu \mathrm{g}$ per mouse)]. Proliferation of donor-derived OT-I CD8 ${ }^{+}$and OT-II CD4 ${ }^{+}$ $T$ cells was assessed 4 days after adoptive transfer by flow cytometric analysis of single-cell suspensions from inguinal, "vaccine"-draining LNs. c Histograms show data from one representative experiment. The experiment was performed independently two times with comparable results

therapeutic benefit for the treatment of established tumors than single-agent treatment. Tumor growth was measured in WT mice bearing subcutaneous MC38 tumors treated with ansamitocin P3 alone, anti-PD-1/anti-CTLA-4 antibodies alone, or the combination of both (Fig. 5c, d). Tumor growth was rapid in the control group (0/10 mice were tumor free). Ansamitocin P3 alone or PD-1/CTLA-4-blocking antibodies alone significantly delayed tumor growth and achieved 

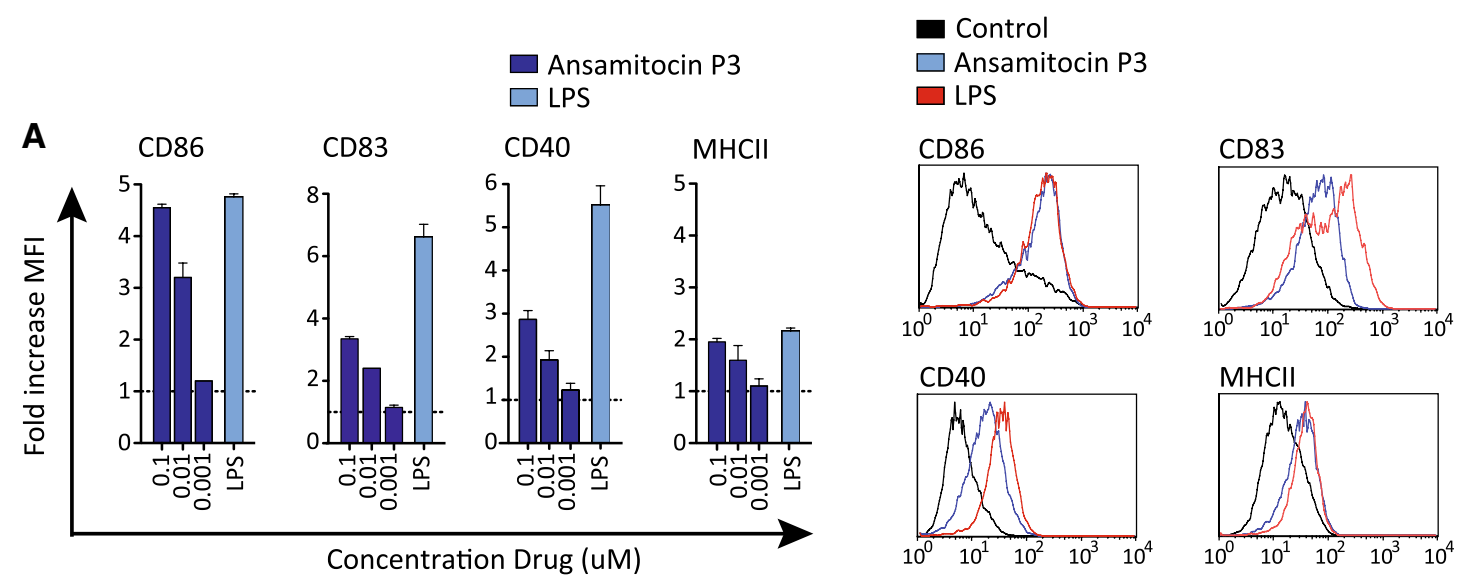

B Mixed Lymphocyte Reaction
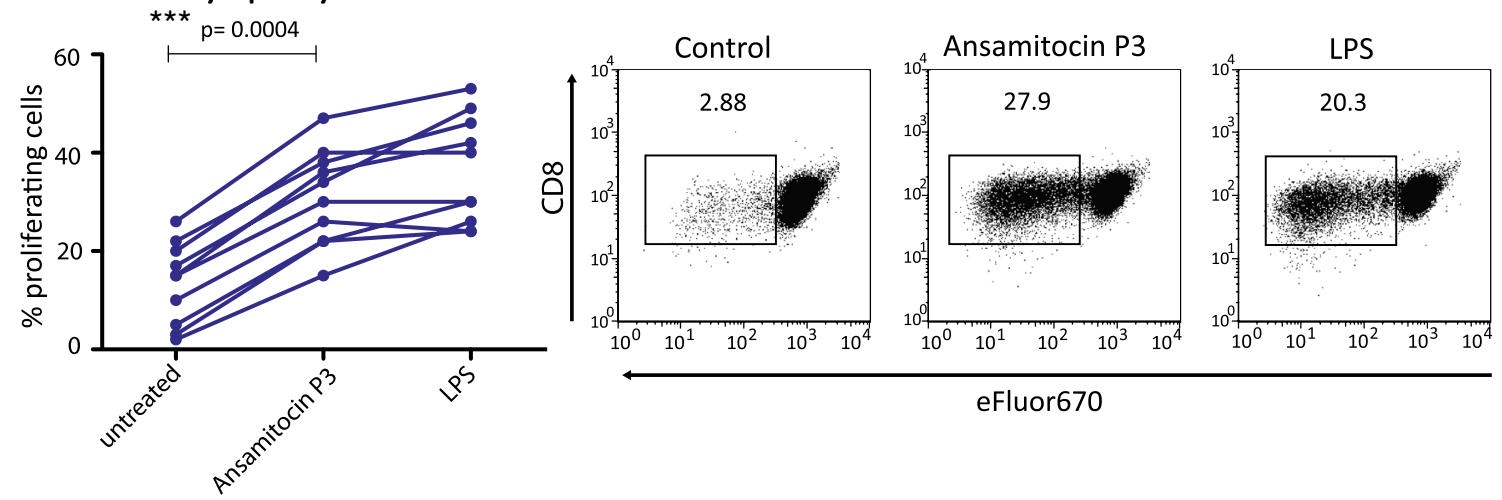

Fig. 4 Ansamitocin P3-treated human DCs up-regulate co-stimulatory molecules and display an enhanced $T$-cell stimulatory capacity. a Concentration-dependent expression of CD86, CD83, CD40, and HLA-DR after $24 \mathrm{~h}$ exposure of human moDCs to ansamitocin P3 or LPS ( $500 \mathrm{ng} / \mathrm{mL}$ ) was assessed by flow cytometry. MFI change compared with mock-treated cells, which were set as 1 , is shown (left panel). All data are representative of at least three independent experiments. Data are depicted as mean \pm SD. Representative histo-

complete eradication of tumors in $1 / 12$ and 4/12 mice, respectively. Importantly, a strong synergism was seen with combination treatment (tumor eradication in 9/11 mice).

To further delineate this synergy, we analyzed the change in the composition as well as functionality of tumor-infiltrating immune cells, in particular considering the frequency of $\mathrm{CD} 4{ }^{+} \mathrm{CD} 25^{+} \mathrm{FoxP}^{+}{ }^{+}$Tregs [26] and the intratumoral effector $T$ cell to Treg ratio [27]. To this end, tumor-bearing mice were treated with ansamitocin P3 alone, anti-PD-1/CTLA-4 antibodies alone, or the combination of both, and tumor-infiltrating immune cells were analyzed (Fig. 6a). In particular for the latter group, we observed a decrease in the percentage of tumor-infiltrating $\mathrm{CD} 4^{+} \mathrm{CD} 25^{+} \mathrm{FoxP}^{+}$Treg cells, while IFN- $\gamma$ producing infiltrating $\mathrm{CD} 4^{+}$and $\mathrm{CD}^{+}$effector $T$ cells substantially increased (Fig. 6b, c). This resulted in a shift from a low to high effector to $\mathrm{T}$ regulatory cell ratio upon treatment with the combination therapy. $\mathrm{CD} 11 \mathrm{~b}^{+} \mathrm{F} 4 / 80^{+}$ grams for CD83, CD86, CD40, and HLA-DR expression are shown (right panel). Control cells were incubated with vehicle alone. b Monocyte-derived DCs were exposed to ansamitocin P3 or LPS and subsequently used to stimulate allogeneic $\mathrm{CD}^{+} T$ cells in a mixed lymphocyte reaction. $T$ cell proliferation was measured after 4 days. The experiments were repeated with PBMCs from eight healthy blood donors yielding similar results (left panel). Representative flow cytometry plots of one experiment are shown (right panel)

tumor-associated macrophages (TAM) are a distinct population of infiltrating myeloid cells, which are capable of promoting tumor growth and angiogenesis [28]. We observed a

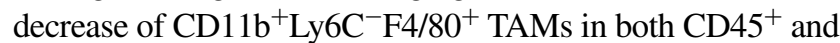
$\mathrm{CD}_{1} 1 \mathrm{~b}^{+}$populations upon treatment with ansamitocin $\mathrm{P} 3$, which was even more pronounced in the combination group. Overall, the changes in the intratumoral effector $T$ cell to Treg ratio and the abundance of $\mathrm{CD} 11 \mathrm{~b}^{+} \mathrm{Ly} 6 \mathrm{C}^{-} \mathrm{F} 4 / 80^{+} \mathrm{TAMs}$, which reflect a shift toward an immunologically permissive microenvironment, provide a mechanistic explanation of the therapeutic efficacy of the combination therapy.

\section{Discussion}

In this study, we demonstrate that both adaptive and innate immunity are critically required for the therapeutic 
Fig. 5 The efficacy of ansamitocin $\mathrm{P} 3$ treatment is dependent on $\mathrm{CD} 11 \mathrm{c}^{+} \mathrm{DCs}$, IFN- $\gamma$, and adaptive immunity and synergizes with antibody-mediated blockade of $T$ cell inhibitory receptors PD- 1 and CTLA-4. a $\mathrm{WT}, \operatorname{Rag} 2^{-/-}$, and IFN- $\gamma \mathrm{R}^{-l-}$ mice bearing s.c. EG-7 tumors received intratumoral injections of ansamitocin P3 $(0.3 \mathrm{mg} /$ $\mathrm{kg}$ ) or vehicle (PBS). b Tumor (3LL-Thy1.1-OVA) growth in WT and CD11c-DTR/GFP mice upon treatment with ansamitocin P3. DT was used for depletion of $\mathrm{CD} 11 \mathrm{c}^{+}$cells in CD11c-DTR/GFP mice. PBS or PBS + DT was injected in control mice. Results represent pooled data from two independent experiments. c Ansamitocin P3 (0.3 mg/kg), anti-PD-1/antiCTLA-4 mAbs, or the combination of both was administered in C57BL/6 mice bearing 16-day established subcutaneous MC38 tumors. Treatment schedule is detailed in the materials and methods section. Control tumorbearing mice received matched isotype control antibodies. Results represent pooled data from two independent experiments and are depicted as (c) individual tumor growth curves or $\mathbf{d}$ cumulative tumor volume over time and as a KaplanMeier survival plot
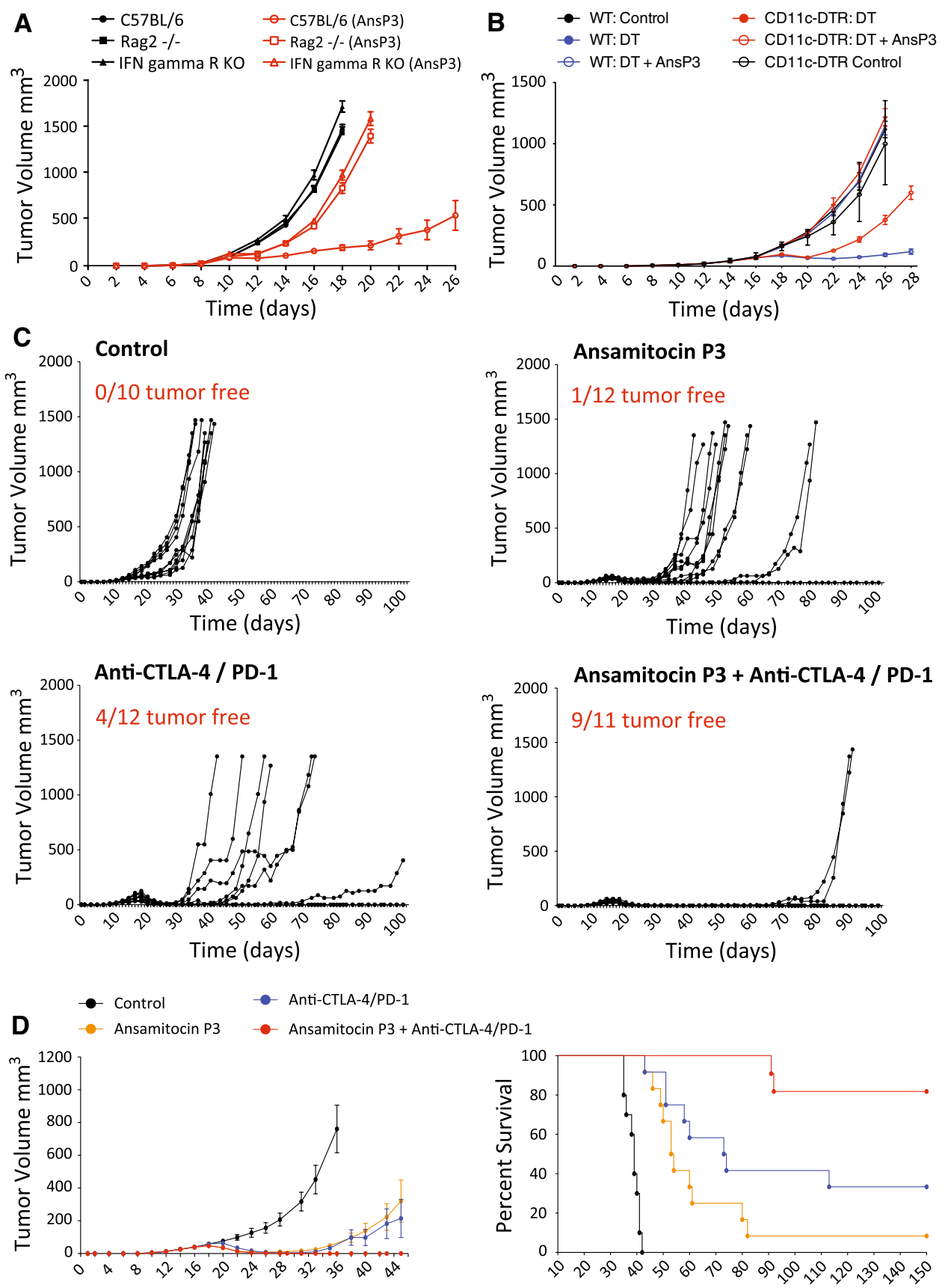

anti-tumor efficacy of ansamitocin P3, a structural analog of maytansine [29-31]. Maytansine derivatives are tubulinbinding agents, which have shown significant activity in various cancer types. Though systemic administration of free maytansinoids has demonstrated substantial toxicity, the wide therapeutic index of antibody-drug conjugates (ADCs) has lead to the exploration of maytansine derivatives as cytotoxic payloads of ADCs, which allows a tumortargeted delivery, a key determinant of clinical activity and tolerability [32]. In addition, the development of synthetic derivatives of maytansine has been instigated that possess a 100- to 1,000-fold higher cytotoxic potency than clinically used anticancer drugs such as Vinca alkaloids [33]. While trastuzumab emtansine (T-DM1) has recently been approved in Her2-positive breast cancer, maytansinoid-conjugated antibodies such as BT062, SAR3419, BAY94-9343, and IMGN529 are currently under clinical evaluation in phase I/II protocols [34]. Here, we report that ansamitocin P3 induces a potent phenotypic and functional maturation of both murine and human DC populations. Consequently, ansamitocin P3 exposed DCs displayed an enhanced capacity to activate $T$ cells both in vitro and in vivo. Of note, these effects have been observed even in the absence of tumor cell death. Maturation of DCs in 
vivo resulted in extensive homing of tumor-resident DCs to the tumor-draining lymph node. Although ansamitocin P3 exerts direct cytotoxic effects on tumor cells, its therapeutic efficacy critically required an intact immune system. In particular, utilizing depletion experiments, we showed that the anti-tumor effect in vivo was largely dependent on $\mathrm{CD} 11 \mathrm{c}^{+}$DCs. To the best of our knowledge, this report is the first to demonstrate that ansamitocin P3 exerts an immunostimulatory function, mainly by modulating the anti-tumor immune response through activation of DCs.

In our initial analysis of a broad panel of cytotoxic compounds, we recognized that most notably microtubule-targeting agents were able to induce maturation of DCs. The observed effect was particularly pronounced for microtubule-destabilizing agents and associated with substantial up-regulation of maturation markers such as CD86 in both human and murine DCs. This observation is consistent with data from a functional screen of chemotherapeutic agents, which identified microtubule-targeting agents as inducers of DC maturation [14]. Microtubules play key roles in cell proliferation, trafficking, signaling, and migration in eukaryotic cells and are targeted by several anticancer therapies. Microtubule-destabilizing compounds include colchicine, the Vinca alkaloids and maytansines. In contrast to microtubule-stabilizing agents, which mainly bind at the taxane pocket [35], the binding site of ansamitocin $\mathrm{P} 3$ on $\beta$-tubulin partially overlaps with the vinblastine-binding site [36]. Both classes, microtubule-stabilizing and microtubuledestabilizing agents interfere with microtubule dynamics leading to tumor cell apoptosis. It is, however, currently unclear whether their disparate mode of action explains our observed difference in DC activation. Along the same line, and contrasting our findings with ansamitocin P3 in DCs, paclitaxel has been reported to reduce the capacity for endocytosis and production of pro-inflammatory cytokines, thus inhibiting anti-tumor immune responses [37]. Although signaling pathways in DCs remain incompletely understood the microtubule-interfering agents, vinblastine and taxol were shown to evoke distinct signaling through c-Jun/AP-1-dependent and c-Jun/AP-1-independent mechanisms, despite a common activation of the JNK pathway [38]. Further studies are clearly necessary to accurately define signaling pathways and monitor microtubule dynamics in DCs upon exposure to immunostimulatory microtubule inhibitors such as ansamitocin P3.

Dendritic cells (DCs) are an integral component of the tumor-specific immune response due to their capacity to capture, process, and present tumor-derived antigens to $T$ cells [39]. Tumors, however, may interfere with DC maturation and function and promote tumor growth through generation of "pro-tumorigenic DCs" [40-42]. Our findings demonstrate that ansamitocin $\mathrm{P} 3$ is capable to induce maturation and migration of intratumoral DCs to the draining
$\mathrm{LN}$, thereby rewiring these cells into anti-tumor DCs. Consequently, functional tumor antigen-specific $T$ cells are promoted, which in turn may contribute to tumor rejection. In contrast to direct effects on DCs using low non-toxic concentrations of cytotoxic drugs, we have observed effects on DC maturation and $T$ cell activation over a wide range of ansamitocin P3 doses with the highest doses being capable of inducing tumor cell apoptosis in vitro and in vivo. It remains to be determined, which subset of antigen-presenting cells is instrumental in ansamitocin P3 induced immunoactivation in vivo. Ma et al. have previously demonstrated that intratumoral $\mathrm{CD} 11 \mathrm{c}^{+} \mathrm{CD} 11 \mathrm{~b}^{+} \mathrm{Ly} 6 \mathrm{C}^{\mathrm{hi}}$ cells, which exhibit some characteristics of inflammatory DCs [43], are required for the efficacy of anthracycline-based chemotherapy [44]. Our data do not exclude the possibility that malignant cells, which undergo cell death upon injection of ansamitocin P3, release signals, which further amplify the anti-tumor immune response. Distinct molecular mediators either exposed on the cell surface or released into the extracellular space have been associated with immunogenic cell death induced by anthracyclines as well as oxaliplatin [8]. Such molecular mediators include calreticulin, ATP, and high-mobility group box 1 (HMGB1) [8]. Although we have demonstrated pronounced activation of OVA-specific $\mathrm{CD}^{+}$and $\mathrm{CD} 4^{+} T$ cells in the absence of tumor cell death, further investigations are necessary to explore the precise molecular events induced by ansamitocin P3.

Impressive clinical success has been achieved by novel cancer immunotherapies that target immunoregulatory checkpoints on $T$ cells [45-47]. Only recently and in accordance with preclinical data from a murine B16 melanoma model [48], unprecedented clinical benefits with rapid and deep responses have been reported with concurrent CTLA-4/PD-1 blockade [3]. Our data suggest that upon treatment with ansamitocin $\mathrm{P} 3$, specific $T$ cell responses are augmented, which may be potentially rendered dysfunctional in tumor-bearing hosts. We thus explored a functional interplay between ansamitocin P3 and CTLA-4/PD-1 blocking antibodies. Indeed, the combination was significantly more potent against established tumors than ansamitocin P3 or antibodies alone. Reflecting the therapeutic benefit of the combination, we demonstrated a significant decrease in the percentage of tumorresident Tregs and increase in IFN- $\gamma$-producing $T$ effector cells. In addition, we noticed a significant decrease in the proportion TAM, which are often pro-tumorigenic [49].

Our study identifies a novel mechanism of immune engagement by ansamitocin P3 in tumor-bearing hosts through triggering functional maturation of DCs. This is of clinical relevance as the excitement over antibody-maytansinoid conjugates is steadily building, and this class of drugs is readily integrated into the treatment regimen of 
Tumor cell injection

$\checkmark$ Anti-CTLA4/PD-1 (250 ug, i.p.)

$\checkmark$ AnsP3 $(0.3 \mathrm{mg} / \mathrm{kg}$, i.v.)

A

$\checkmark$ Analysi

Anti - CTLA4/PD -1

INWWWWWWMWWWWWW

\begin{tabular}{llllll}
\hline 0 & 1214 & 16 & 21 & 24 & 26
\end{tabular}

AnsP3

WWWWWWWWWMWWWWM

\begin{tabular}{llllll}
\hline 0 & 121416 & 1921 & 24 & 26
\end{tabular}

Anti - CTLA4/PD -1 + AnsP3

VWWWWWWMWMWMWMV
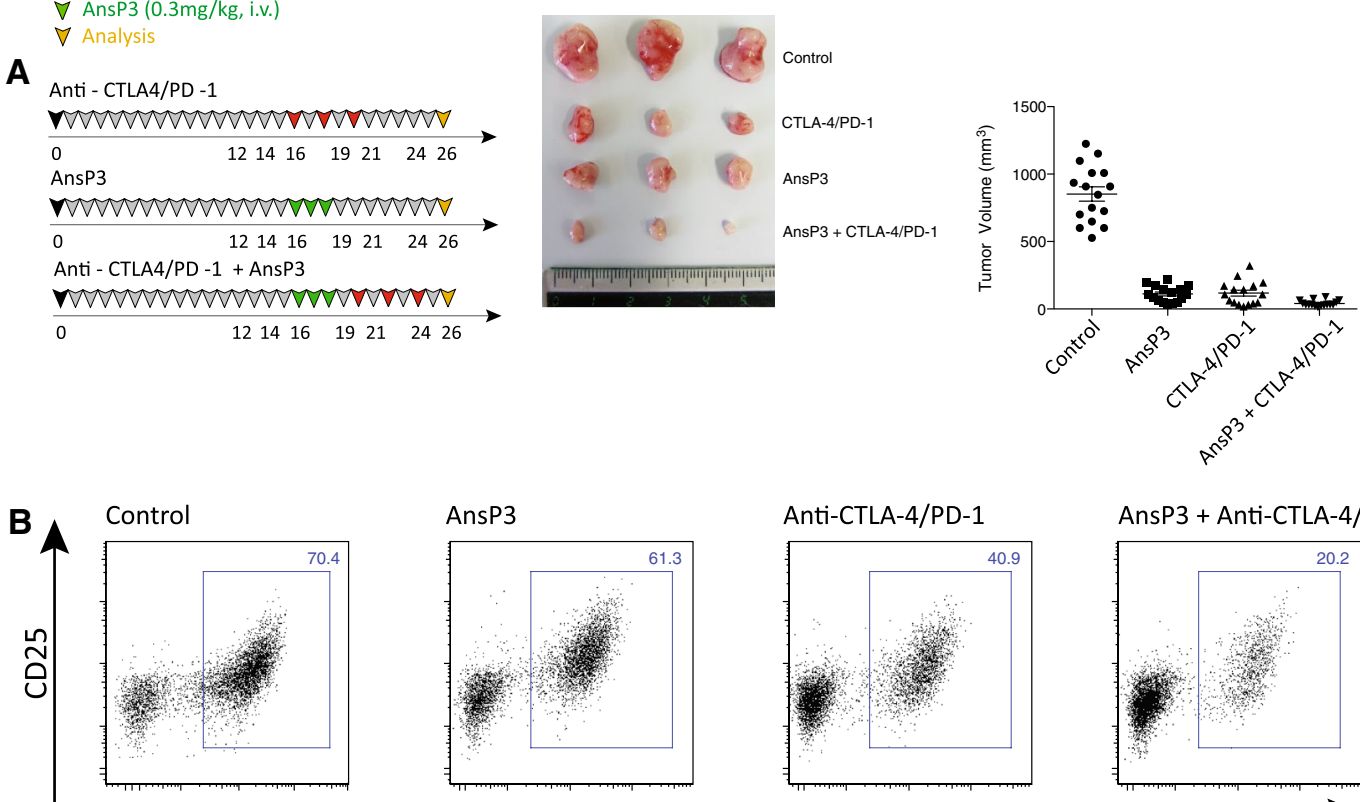

Anti-CTLA-4/PD-1

AnsP3 + Anti-CTLA-4/PD-1
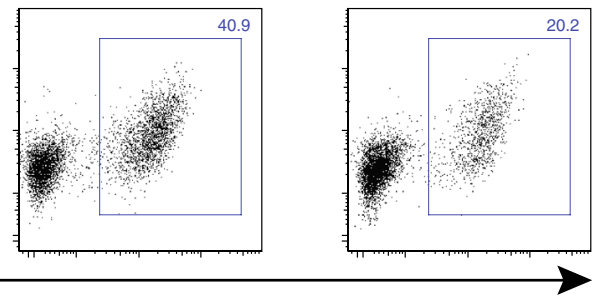

FoxP3

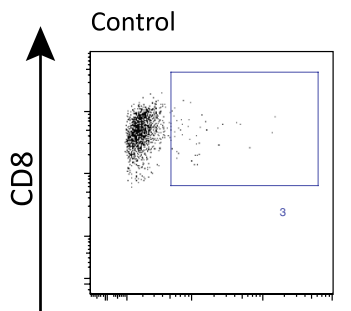

AnsP3

Anti-CTLA-4/PD-1

AnsP3 + Anti-CTLA-4/PD-1
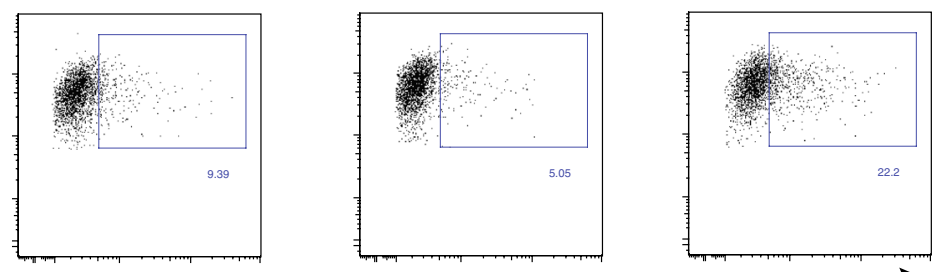

IFN (gamma)

C
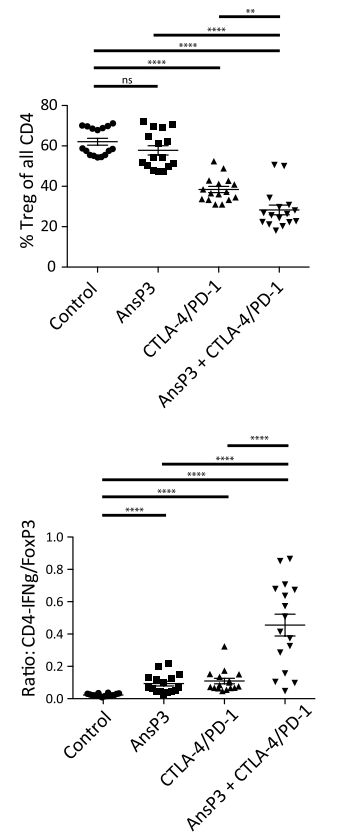
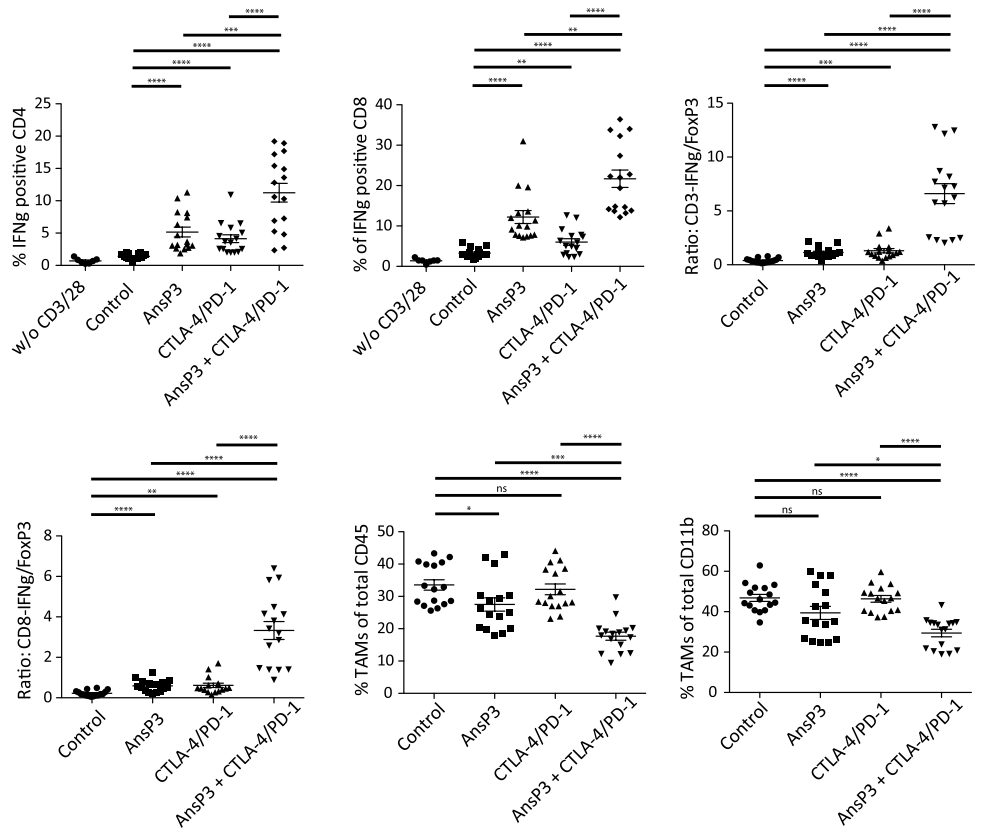
4 Fig. 6 Combination treatment of ansamitocin P3 and antiCTLA-4/PD-1 induces interferon- $\gamma$ production in tumor-infiltrating $\mathrm{CD}^{+} T$ cells and decreases the frequency of intratumoral $\mathrm{CD} 4{ }^{+} \mathrm{CD} 25^{+} \mathrm{FoxP}^{+}$Tregs as well as TAMs. a C57BL/6 mice bearing established MC38 tumors were treated as indicated; tumor size in control and treatment groups at the day of analysis (day 26). $\mathbf{b}+\mathbf{c}$ Tumors were dissociated and analyzed for $\mathrm{CD} 4^{+} \mathrm{CD} 25^{+} \mathrm{FoxP} 3^{+}$ Tregs, IFN $-\gamma^{+} \mathrm{CD}^{+}$as well as IFN- $\gamma^{+} \mathrm{CD} 4^{+} T$ cells and $\mathrm{CD} 45^{+}$ $\mathrm{CD} 11 \mathrm{~b}^{+} \mathrm{Ly} 6 \mathrm{C}^{-} \mathrm{F} 4 / 80^{+}$TAMs by flow cytometry. b Representative dot plots for the expression of $\mathrm{CD} 25$ and FoxP3 on $\mathrm{CD} 4{ }^{+}$ cells and IFN- $\gamma$ on $\mathrm{CD}^{+}$cells are shown. c Graphs depict the frequency of the indicated tumor-infiltrating lymphocytic subsets (from left to right, top row: $\% \mathrm{CD}^{+} \mathrm{CD} 25^{+} \mathrm{FoxP} 3^{+}$Tregs of total $\mathrm{CD}^{+} ; \% \mathrm{CD} 4^{+} \mathrm{IFN}-\gamma^{+}$of total $\mathrm{CD} 4^{+} ; \% \mathrm{CD}^{+}$IFN- $\gamma^{+}$ of total $\mathrm{CD}^{+}$; ratio $\mathrm{CD} 3^{+} \mathrm{IFN}-\gamma^{+}$to Tregs; from left to right, bottom row: ratio $\mathrm{CD}^{+} \mathrm{IFN}-\gamma^{+}$to Tregs; ratio $\mathrm{CD} 8^{+} \mathrm{IFN}-\gamma^{+}$to Tregs; $\%$ TAMs $\left(\mathrm{CD} 11 \mathrm{~b}^{+} \mathrm{Ly}_{6 \mathrm{C}^{-}} \mathrm{F} 4 / 80^{+}\right)$of total $\mathrm{CD} 45^{+}$and \% TAMs $\left(\mathrm{Ly} 6 \mathrm{C}^{-} \mathrm{F} 4 / 80^{+}\right)$of total $\left.\mathrm{CD} 11 \mathrm{~b}^{+}\right)$. Results represent pooled data from three independent experiments (mean \pm SEM)

cancer patients. Moreover, using CTLA-4/PD-1-blocking antibodies in combination with ansamitocin P3, we have identified a potent novel therapeutic strategy, which warrants further investigation into preclinical models and early clinical trials.

Acknowledgments This work was supported by grants from the Swiss National Science Foundation, the Wilhelm-Sander-Foundation, the Cancer League Basel, and the Huggenberger Stiftung. We thank Béatrice Dolder-Schlienger, Mélanie Buchi, and Petra Herzig for excellent technical assistance; Arne Sutter (Merck KGaA) for providing the SP37A3 cell line; the Developmental Therapeutics Program at $\mathrm{NCI} / \mathrm{NIH}$ for providing ansamitocin $\mathrm{P} 3$, vinblastine, vindesine, and vinorelbine; Jean Pieters for providing OT-II mice; and Douglas Fearon and Mark Smyth for providing tumor cell lines. Furthermore, we thank Heinz Läubli, Narasimha Rao Uda, and Matthias Kreuzaler for critical reading of the manuscript.

Conflict of interest The authors declare no conflicts of interest.

\section{References}

1. Drake CG, Lipson EJ, Brahmer JR (2014) Breathing new life into immunotherapy: review of melanoma, lung and kidney cancer. Nat Rev Clin Oncol 11(1):24-37. doi:10.1038/nrclin onc. 2013.208

2. Hamid O, Robert C, Daud A, Hodi FS, Hwu WJ, Kefford R, Wolchok JD, Hersey P, Joseph RW, Weber JS, Dronca R, Gangadhar TC, Patnaik A, Zarour H, Joshua AM, Gergich K, Elassaiss-Schaap J, Algazi A, Mateus C, Boasberg P, Tumeh PC, Chmielowski B, Ebbinghaus SW, Li XN, Kang SP, Ribas A (2013) Safety and tumor responses with lambrolizumab (anti-PD-1) in melanoma. N Engl J Med. doi:10.1056/NEJ Moa1305133

3. Wolchok JD, Kluger H, Callahan MK, Postow MA, Rizvi NA, Lesokhin AM, Segal NH, Ariyan CE, Gordon RA, Reed K, Burke MM, Caldwell A, Kronenberg SA, Agunwamba BU, Zhang X, Lowy I, Inzunza HD, Feely W, Horak CE, Hong Q, Korman AJ, Wigginton JM, Gupta A, Sznol M (2013) Nivolumab plus ipilimumab in advanced melanoma. N Engl J Med. doi:10.1056/NEJ Moa1302369
4. Bracci L, Schiavoni G, Sistigu A, Belardelli F (2014) Immunebased mechanisms of cytotoxic chemotherapy: implications for the design of novel and rationale-based combined treatments against cancer. Cell Death Differ 21(1):15-25. doi:10.1038/ cdd. 2013.67

5. Chen G, Emens LA (2013) Chemoimmunotherapy: reengineering tumor immunity. Cancer Immunol Immunother 62(2):203-216. doi:10.1007/s00262-012-1388-0

6. Lake RA, Robinson BW (2005) Immunotherapy and chemotherapy - a practical partnership. Nat Rev Cancer 5(5):397-405

7. Gajewski TF, Schreiber H, Fu YX (2013) Innate and adaptive immune cells in the tumor microenvironment. Nat Immunol 14(10):1014-1022. doi:10.1038/ni.2703

8. Zitvogel L, Galluzzi L, Smyth MJ, Kroemer G (2013) Mechanism of action of conventional and targeted anticancer therapies: reinstating immunosurveillance. Immunity 39(1):74-88. doi:10.1016/j.immuni.2013.06.014

9. Palucka K, Banchereau J (2012) Cancer immunotherapy via dendritic cells. Nat Rev Cancer 12(4):265-277. doi:10.1038/nrc3258

10. Hargadon KM (2013) Tumor-altered dendritic cell function: implications for anti-tumor immunity. Front Immunol 4:192. doi: 10.3389/fimmu.2013.00192

11. Kroemer G, Galluzzi L, Kepp O, Zitvogel L (2013) Immunogenic cell death in cancer therapy. Annu Rev Immunol 31:51-72. doi:10.1146/annurev-immunol-032712-100008

12. van de Ven R, Reurs AW, Wijnands PG, van Wetering S, Kruisbeek AM, Hooijberg E, Scheffer GL, Scheper RJ, de Gruijl TD (2012) Exposure of CD34+ precursors to cytostatic anthraquinone-derivatives induces rapid dendritic cell differentiation: implications for cancer immunotherapy. Cancer Immunol Immunother 61(2):181-191. doi:10.1007/s00262-011-1039-x

13. Mizumoto N, Gao J, Matsushima H, Ogawa Y, Tanaka H, Takashima A (2005) Discovery of novel immunostimulants by dendritic-cell-based functional screening. Blood 106(9):30823089. doi:10.1182/blood-2005-03-1161

14. Tanaka H, Matsushima H, Mizumoto N, Takashima A (2009) Classification of chemotherapeutic agents based on their differential in vitro effects on dendritic cells. Cancer Res 69(17):69786986. doi:10.1158/0008-5472.CAN-09-1101

15. Tanaka H, Matsushima H, Nishibu A, Clausen BE, Takashima A (2009) Dual therapeutic efficacy of vinblastine as a unique chemotherapeutic agent capable of inducing dendritic cell maturation. Cancer Res 69(17):6987-6994. doi:10.1158/0008-5472. CAN-09-1106

16. Nalbandian G, Paharkova-Vatchkova V, Mao A, Nale S, Kovats S (2005) The selective estrogen receptor modulators, tamoxifen and raloxifene, impair dendritic cell differentiation and activation. $\mathrm{J}$ Immunol 175(4):2666-2675

17. Hipp MM, Hilf N, Walter S, Werth D, Brauer KM, Radsak MP, Weinschenk T, Singh-Jasuja H, Brossart P (2008) Sorafenib, but not sunitinib, affects function of dendritic cells and induction of primary immune responses. Blood 111(12):5610-5620. doi:10.1182/blood-2007-02-075945

18. Bros M, Jahrling F, Renzing A, Wiechmann N, Dang NA, Sutter A, Ross R, Knop J, Sudowe S, Reske-Kunz AB (2007) A newly established murine immature dendritic cell line can be differentiated into a mature state, but exerts tolerogenic function upon maturation in the presence of glucocorticoid. Blood 109(9):38203829. doi:10.1182/blood-2006-07-035576

19. Abeyama K, Eng W, Jester JV, Vink AA, Edelbaum D, Cockerell CJ, Bergstresser PR, Takashima A (2000) A role for NFkappaB-dependent gene transactivation in sunburn. J Clin Invest 105(12):1751-1759. doi:10.1172/JCI9745

20. Daniels MA, Teixeiro E, Gill J, Hausmann B, Roubaty D, Holmberg K, Werlen G, Hollander GA, Gascoigne NR, Palmer E (2006) Thymic selection threshold defined by compartmentalization of 
Ras/MAPK signalling. Nature 444(7120):724-729. doi:10.1038/ nature 05269

21. Meidenbauer N, Zippelius A, Pittet MJ, Laumer M, Vogl S, Heymann J, Rehli M, Seliger B, Schwarz S, Le Gal FA, Dietrich PY, Andreesen R, Romero P, Mackensen A (2004) High frequency of functionally active melan-a-specific $\mathrm{T}$ cells in a patient with progressive immunoproteasome-deficient melanoma. Cancer Res 64(17):6319-6326. doi:10.1158/0008-5472.CAN-04-1341

22. West MA, Wallin RP, Matthews SP, Svensson HG, Zaru R, Ljunggren HG, Prescott AR, Watts C (2004) Enhanced dendritic cell antigen capture via toll-like receptor-induced actin remodeling. Science 305(5687):1153-1157. doi:10.1126/science.1099153

23. West AC, Mattarollo SR, Shortt J, Cluse LA, Christiansen AJ, Smyth MJ, Johnstone RW (2013) An intact immune system is required for the anticancer activities of histone deacetylase inhibitors. Cancer Res. doi:10.1158/0008-5472.CAN-13-0890

24. Mattarollo SR, Loi S, Duret H, Ma Y, Zitvogel L, Smyth MJ (2011) Pivotal role of innate and adaptive immunity in anthracycline chemotherapy of established tumors. Cancer Res 71(14):4809-4820. doi:10.1158/0008-5472.CAN-11-0753

25. Probst HC, McCoy K, Okazaki T, Honjo T, van den Broek M (2005) Resting dendritic cells induce peripheral CD8+ T cell tolerance through PD-1 and CTLA-4. Nat Immunol 6(3):280-286. doi:10.1038/ni1165

26. Nishikawa H, Sakaguchi S (2010) Regulatory T cells in tumor immunity. Int J Cancer 127(4):759-767. doi:10.1002/ijc. 25429

27. Waitz R, Solomon SB, Petre EN, Trumble AE, Fasso M, Norton L, Allison JP (2012) Potent induction of tumor immunity by combining tumor cryoablation with anti-CTLA-4 therapy. Cancer Res 72(2):430-439. doi:10.1158/0008-5472.CAN-11-1782

28. Mantovani A, Germano G, Marchesi F, Locatelli M, Biswas SK (2011) Cancer-promoting tumor-associated macrophages: new vistas and open questions. Eur J Immunol 41(9):2522-2525. doi: 10.1002/eji.201141894

29. Liu C, Chari RV (1997) The development of antibody delivery systems to target cancer with highly potent maytansinoids. Expert Opin Investig Drugs 6(2):169-172. doi:10.1517/13543784.6.2.169

30. Cassady JM, Chan KK, Floss HG, Leistner E (2004) Recent developments in the maytansinoid antitumor agents. Chem Pharm Bull (Tokyo) 52(1):1-26

31. Issell BF, Crooke ST (1978) Maytansine. Cancer Treat Rev 5(4):199-207

32. Alley SC, Okeley NM, Senter PD (2010) Antibody-drug conjugates: targeted drug delivery for cancer. Curr Opin Chem Biol 14(4):529-537. doi:10.1016/j.cbpa.2010.06.170

33. Chari RV, Martell BA, Gross JL, Cook SB, Shah SA, Blattler WA, McKenzie SJ, Goldmacher VS (1992) Immunoconjugates containing novel maytansinoids: promising anticancer drugs. Cancer Res 52(1):127-131

34. Sievers EL, Senter PD (2013) Antibody-drug conjugates in cancer therapy. Annu Rev Med 64:15-29. doi:10.1146/annurev-med-050311-201823

35. Prota AE, Bargsten K, Zurwerra D, Field JJ, Diaz JF, Altmann KH, Steinmetz MO (2013) Molecular mechanism of action of microtubule-stabilizing anticancer agents. Science 339(6119):587-590. doi:10.1126/science.1230582

36. Venghateri JB, Gupta TK, Verma PJ, Kunwar A, Panda D (2013) Ansamitocin p3 depolymerizes microtubules and induces apoptosis by binding to tubulin at the vinblastine site. PLoS one 8(10):e75182. doi:10.1371/journal.pone.0075182
37. John J, Ismail M, Riley C, Askham J, Morgan R, Melcher A, Pandha H (2010) Differential effects of paclitaxel on dendritic cell function. BMC Immunol 11:14. doi:10.1186/1471-2172-11-14

38. Kolomeichuk SN, Terrano DT, Lyle CS, Sabapathy K, Chambers TC (2008) Distinct signaling pathways of microtubule inhibitors-vinblastine and taxol induce JNKdependent cell death but through AP-1-dependent and AP-1-independent mechanisms, respectively. FEBS J 275(8):1889-1899. doi:10.1111/j.1742-4658.2008.06349.x

39. Banchereau J, Steinman RM (1998) Dendritic cells and the control of immunity. Nature 392(6673):245-252. doi:10.1038/32588

40. Fiorentino DF, Zlotnik A, Vieira P, Mosmann TR, Howard M, Moore KW, O'Garra A (1991) IL-10 acts on the antigen-presenting cell to inhibit cytokine production by Th1 cells. J Immunol 146(10):3444-3451

41. Steinbrink K, Wolfl M, Jonuleit H, Knop J, Enk AH (1997) Induction of tolerance by IL-10-treated dendritic cells. J Immunol 159(10):4772-4780

42. De Monte L, Reni M, Tassi E, Clavenna D, Papa I, Recalde H, Braga M, Di Carlo V, Doglioni C, Protti MP (2011) Intratumor $\mathrm{T}$ helper type 2 cell infiltrate correlates with cancer-associated fibroblast thymic stromal lymphopoietin production and reduced survival in pancreatic cancer. J Exp Med 208(3):469-478. doi:10. 1084/jem.20101876

43. Cheong C, Matos I, Choi JH, Dandamudi DB, Shrestha E, Longhi MP, Jeffrey KL, Anthony RM, Kluger C, Nchinda G, Koh H, Rodriguez A, Idoyaga J, Pack M, Velinzon K, Park CG, Steinman RM (2010) Microbial stimulation fully differentiates monocytes to DC-SIGN/CD209 (+) dendritic cells for immune T cell areas. Cell 143(3):416-429. doi:10.1016/j.cell.2010.09.039

44. Ma Y, Adjemian S, Mattarollo SR, Yamazaki T, Aymeric L, Yang H, Portela Catani JP, Hannani D, Duret H, Steegh K, Martins I, Schlemmer F, Michaud M, Kepp O, Sukkurwala AQ, Menger L, Vacchelli E, Droin N, Galluzzi L, Krzysiek R, Gordon S, Taylor PR, Van Endert P, Solary E, Smyth MJ, Zitvogel L, Kroemer G (2013) Anticancer chemotherapy-induced intratumoral recruitment and differentiation of antigen-presenting cells. Immunity 38(4):729-741. doi:10.1016/j.immuni.2013.03.003

45. Robert C, Thomas L, Bondarenko I, O’Day S, M DJ, Garbe C, Lebbe C, Baurain JF, Testori A, Grob JJ, Davidson N, Richard J, Maio M, Hauschild A, Miller WH, Gascon P, Lotem M, Harmankaya K, Ibrahim R, Francis S, Chen TT, Humphrey R, Hoos A, Wolchok JD (2011) Ipilimumab plus dacarbazine for previously untreated metastatic melanoma. N Engl J Med 364(26):25172526. doi:10.1056/NEJMoa1104621

46. Topalian SL, Drake CG, Pardoll DM (2012) Targeting the PD-1/ B7-H1 (PD-L1) pathway to activate anti-tumor immunity. Curr Opin Immunol 24(2):207-212. doi:10.1016/j.coi.2011.12.009

47. Hamid O, Carvajal RD (2013) Anti-programmed death-1 and anti-programmed death-ligand 1 antibodies in cancer therapy. Expert Opin Biol Ther 13(6):847-861. doi:10.1517/14712598.20 13.770836

48. Curran MA, Montalvo W, Yagita H, Allison JP (2010) PD-1 and CTLA-4 combination blockade expands infiltrating $\mathrm{T}$ cells and reduces regulatory $\mathrm{T}$ and myeloid cells within B16 melanoma tumors. Proc Natl Acad Sci 107(9):4275-4280. doi:10.1073/p nas.0915174107

49. Sica A, Mantovani A (2012) Macrophage plasticity and polarization: in vivo veritas. J Clin Invest 122(3):787-795. doi:10.1172/JCI59643 